\title{
Effects of high concentrations of hyaluronan in culture medium on development and survival rates of fresh and frozen-thawed bovine embryos produced in vitro
}

\author{
M. Stojkovic ${ }^{1}$, S. Kölle ${ }^{2}$, S. Peinl ${ }^{1}$, P. Stojkovic ${ }^{1}$, \\ V. Zakhartchenko ${ }^{1}$, J. G. Thompson ${ }^{3}, \mathrm{H}$. Wenigerkind ${ }^{4}$, \\ H-D. Reichenbach ${ }^{5}$, F. Sinowatz ${ }^{2}$ and E. Wolf ${ }^{1}$ \\ ${ }^{1}$ Department of Molecular Animal Breeding and Biotechnology, Hackerstr. 27, \\ D-85764 Oberschleissheim, Germany; ${ }^{2}$ Department of Veterinary Anatomy II, \\ Veterinärstr. 13, D-80539 Munich, Germany; ${ }^{3}$ Obstetrics and Gynecology, University \\ of Adelaide, TQEH, Woodville, SA 5011, Australia; ${ }^{4}$ Bavarian Research Center for \\ Reproductive Biology (BFZF), D-85764 Oberschleissheim, Germany; and ${ }^{5}$ Bavarian \\ Research Station for Animal Breeding, D-85586 Poing, Germany
}

Hyaluronic acid (HA) is the main glycosaminoglycan present in follicular, oviductal and uterine fluids. The main functions of $\mathrm{HA}$ include dynamic processes that are mediated through interaction with extracellular matrix components, regulation of gene expression, cell proliferation and cell differentiation. HA increases the viscosity of solutions and also has several physiological functions, including regulation of water distribution and waterbinding capacity. The addition of $6 \mathrm{mg} \mathrm{HA} \mathrm{ml}^{-1}$ to synthetic oviduct fluid (SOF; SOF-HA) culture medium on day 5 $(I V F=$ day 0$)$ significantly $(P<0.001)$ increased the viscosity of the medium in comparison with SOF culture medium containing BSA (SOF-BSA). On day 8, rate of blastocyst development in SOF-HA culture medium was significantly $(P<0.05)$ higher than in SOF-BSA culture medium $(38.2$ versus $29.3 \%$ ). The number of trophectoderm cells and the total number of cells of expanded blastocysts cultured in the presence of HA were significantly $(P<0.01)$ higher in comparison with expanded blastocysts cultured in the presence of BSA $(88.9 \pm 7.3$ versus $67.6 \pm 3.0$ and $130.1 \pm 10.9$ versus $104.8 \pm 2.5$, respectively). After freezing and thawing, the percentage of day 8 embryos that re-expanded and hatched when cultured with SOF-HA was greater than that of embryos cultured with SOF-BSA (11.3 and $10.5 \%$ versus 75.5 and $36.8 \%$, respectively). After thawing, the ATP contents of in vivo-derived, SOF-HA and SOF-BSA expanded blastocysts were similar. The embryos cultured with HA showed less ultrastructural deviation and de-differentiation after freezing and thawing than the embryos cultured with BSA. This study demonstrates that HA improves the developmental capacity of bovine embryos under in vitro conditions and is warranted as a supplement for in vitro production of bovine embryos, particularly if they are to be cryopreserved.

\section{Introduction}

The most critical step in the production of bovine embryos from oocytes matured and fertilized in vitro is perhaps the culture of the presumptive zygotes to the blastocyst stage. One of the most widely used supplements for in vitro culture of bovine embryos is serum, which reduces early developmental potential of embryos (Bavister, 1995), causes abnormal metabolic and ultrastructural configuration of embryos (Abe et al., 1999; Crosier et al., 2001; Stojkovic et al., 2001a) and at the same time increases the sensitivity of embryos to cryopreservation and compromises viability of these embryos, as indicated by the rates of embryo survival after thawing (Vajta et al., 1997; Ohboshi et al., 1998) and pregnancy rates (Massip et al., 1995).

Email:M.Stojkovic@gen.vetmed.uni-muenchen.de
Most studies have focused on creating suitable chemically defined serum-free media to avoid these problems and to increase the developmental potential of bovine embryos produced in vitro. Unfortunately, the physical, particularly rheological properties of culture media are often overlooked. Among those, viscosity of culture medium, defined as a property of a fluid to resist flowing when subjected to an applied force, may play an important role. Highly viscous fluids are often composed of large, complicated molecules that influence the resorption ability, kinetics and release of drugs and nutritional elements from these fluids (Jackson et al., 1991; Nishida et al., 2000).

Stojkovic et al. (1999a) demonstrated that a high concentration of hyaluronic acid, a natural high viscosity mucopolysaccharide composed of repeating disaccharides (Hoae et al., 1993), is a prospective candidate for increasing the viscosity of culture medium because of its chemical and 
physical properties, and for successfully replacing serum for in vitro culture of bovine embryos. Hyaluronic acid or hyaluronan (HA, which includes the different forms that the molecule can take, for example, the acid form, hyaluronic acid, and the salts, such as sodium hyaluronate, which is formed at physiological $\mathrm{pH}$ ) is the major glycosaminoglycan present in follicular, oviductal and uterine fluids (Lee and Ax, 1979; Suchanek et al., 1994; Rodriguez-Martinez et al., 1998). Physiological concentrations of HA in follicular, oviductal and uterine fluids of pigs range from 0.04 to $1.83 \mathrm{mg} \mathrm{HA} \mathrm{ml}^{-1}$ (16-39\% of all glycosaminoglycans; Kano et al., 1998). In addition, HA is secreted by granulosa and expanding cumulus cells (Eppig, 1979; Nagyova et al., 2000). Receptors for HA (CD44) are present in human (Campbell et al., 1995) and bovine (Valcarcel et al., 1999; M. Stojkovic, P. Stranieri, V. Zakhartchenko, E. Wolf, unpublished) oocytes, cumulus cells, early embryos and blastocysts. The main functions of $\mathrm{HA}$ include cell adhesion and migration, dynamic processes that are mediated through interaction with extracellular matrix components (including laminin, elastin, chondroitin sulphate, heparan sulphate), regulation of protein secretion, gene expression, and cell proliferation and differentiation (Scott, 1992; Fraser et al., 1997). As a result of the physicochemical properties of HA solutions, various physiological functions have been assigned, including regulation of protein and water distribution, waterbinding capacity, filtering effects and lubrication.

For these reasons, the aim of the present study was to investigate the effects of high concentrations of HA on the viscosity of culture media, as well as on the rates of cleavage and development to the blastocyst stage, and on survival after freezing of bovine embryos produced in vitro. In addition, the effects of HA on the ultrastructural configuration of fresh and frozen-thawed embryos cultured with or without HA were analysed. As glycosaminoglycans are actively involved in metabolic pathways (Laurent, 1992) and strongly influence adenylate cyclase activity and ATP concentration (Dittmann et al., 1998), total ATP contents of fresh and frozen-thawed embryos of different origin were measured and compared.

Parts of this study were presented at the IETS Meetings 1999 (Stojkovic et al., 1999a) and 2001 (Stojkovic et al., 2001c).

\section{Materials and Methods}

\section{Measurement of viscosity of culture media and follicular fluid}

Viscosities of all culture media before and after filtration and of follicular fluid were measured at $39^{\circ} \mathrm{C}$ using a capillary viscometer (AVS-350; Schott, Hofheim). All samples were measured at least three times and the final viscosity was estimated using Hagenbach's correction coefficient.

\section{Determination of HA concentrations in follicular fluid and oestrous cow serum (ECS)}

Follicular fluid from ovaries of slaughtered German Simmental cows at unknown stages of the oestrous cycle was collected from follicles of $2-8 \mathrm{~mm}$ in diameter, and frozen with other culture media at $-20^{\circ} \mathrm{C}$ until further use. The concentrations of $\mathrm{HA}$ in follicular fluid and culture media were evaluated using a sensitive (detection limit: $<10 \mu \mathrm{g}^{-1}$ ) radiometric assay (HA-Test; Pharmacia Upjohn Diagnostics $A B$, Uppsala), based on the reaction between $\mathrm{HA}$ in the sample and ${ }^{125} \mathrm{I}$-(hyaluronic acid binding proteins)-labelled HA in the assay solution. The unbound 125 -labelled-HABP was quantified by incubation with HA covalently coupled to Sepharose ${ }^{\circledR}$ particles. The radioactivity bound to the particles was measured in a gamma counter (CB 2111; Berthold, Wildbad). All measurements were repeated at least three times.

\section{In vitro production of bovine embryos}

Unless otherwise indicated, all chemicals were purchased from Sigma Chemical Co. (St Louis, MO).

In vitro maturation of oocytes. Bovine oocytes were obtained from cows slaughtered at an abattoir as described by Stojkovic et al. (1995a), with some minor modifications. In brief, follicles $2-8 \mathrm{~mm}$ in diameter were aspirated from ovaries using a 20 gauge needle and a vacuum pressure of approximately $100 \mathrm{~mm} \mathrm{Hg}$. The cumulus-oocyte complexes (COCs) were collected in a $50 \mathrm{ml}$ centrifuge tube and washed twice with pre-incubated $\left(39^{\circ} \mathrm{C} ; 5 \% \mathrm{CO}_{2}\right)$ tissue culture medium 199 (TCM-199) supplemented with $10 \%$ (v/v) ECS. Only COCs with a complete dense cumulus and a dark, evenly granulated cytoplasm (Stojkovic et al., 2001 b) were selected for in vitro maturation. The COCs were washed in TCM-199 supplemented with 10\% (v/v) ECS and 0.01 iu b-FSH and b-LH (Sioux Biochem., Sioux Center, IA) and cultured for maturation in the same medium for $22-24 \mathrm{~h}$ at $39^{\circ} \mathrm{C}$ in $5 \% \mathrm{CO}_{2}$ in air and maximum humidity.

In vitro fertilization. After maturation, COCs were transferred to fertilization medium (Tyrode's albumin lactate pyruvate; Minitüb, Tiefenbach) containing $6 \mathrm{mg}$ BSA (Fraction $\mathrm{V}$ ) $\mathrm{ml}^{-1}$ and $10 \mu \mathrm{g}$ heparin $\mathrm{ml}^{-1}$, and incubated with frozen-thawed semen containing $10^{6}$ spermatozoa $\mathrm{ml}^{-1}$ (German Simmental bull) that had been subjected to a swim-up procedure (Parrish et al., 1986). Gametes were cultured in this medium for $18 \mathrm{~h}$ under the same conditions as those used for in vitro maturation.

In vitro culture. On day 1 (IVF = day 0$)$, cumulus cells were removed from presumptive zygotes by vortexing (120 s) and gentle pipetting. Presumptive zygotes were washed three times in synthetic oviduct fluid medium (Tervit et al., 1972) supplemented with $0.1 \%(\mathrm{v} / \mathrm{v})$ minimum essential medium (MEM), 0.2\% (v/v) basal medium eagle amino acids (SOF) and $1 \mathrm{mg} \mathrm{BSA} \mathrm{ml}^{-1}$ (Fraction $\mathrm{V}$, fatty acid free and low endotoxin; ICN Biomedicals, Eschwege) (SOF-BSA). In nine replicates, 2012 presumptive zygotes were cultured in groups of 10-12 in $20 \mu$ droplets of SOF-BSA until day 5. Subsequently, each group of 10-12 embryos was transferred randomly to either $20 \mu \mathrm{l}$ droplets of fresh SOF-BSA (in total 992 embryos) or $20 \mu$ l droplets of fresh SOF-BSA supplemented with $6 \mathrm{mg} \mathrm{HA-sodium} \mathrm{salt}$ 
$\mathrm{ml}^{-1}$ (SOF-HA) (in total 1020 embryos), recovered from Streptococcus equi sp. (537474; Fluka, Buchs, molecular weight: $\left.1.69 \times 10^{6}\right)$. The concentration and the in vitro culture schedule with HA used in the present study were chosen because it had been demonstrated previously that HA markedly increased the viscosity of the medium and successfully supported in vitro development of bovine embryos (Stojkovic et al., 1999a). HA was solubilized for at least $45 \mathrm{~min}$ at $39^{\circ} \mathrm{C}$. In addition, presumptive zygotes were allocated in our standard conditions, that is, groups of 30-35 presumptive zygotes in $400 \mu \mathrm{l}$ SOF supplemented with $10 \%(v / v)$ ECS (SOF-ECS) for 8 days. Before use, all culture media were pre-equilibrated for $12-14 \mathrm{~h}$ at $39^{\circ} \mathrm{C}$ in a humidified atmosphere of $5 \% \mathrm{CO}_{2}$ in air. Osmolarity of all culture media was measured using a freeze point osmometer (Bachofer, Reutlingen): the readings were 271, 288 and 274 mOsm for SOF-BSA, SOF-HA and SOF-ECS, respectively. The $\mathrm{pH}$ values of culture media before use were measured using pH-meter (WTW Microprocessor, Weilheim) and were 7.46, 7.44 and 7.41 for SOF-BSA, SOF-HA and SOF-ECS, respectively. For all treatments, presumptive zygotes were allocated to all culture media from each in vitro fertilization experiment and cultured in four-well dishes (Nunc, Roskilde) and covered with preequilibrated paraffin oil at $39^{\circ} \mathrm{C}$ in a humidified atmosphere of $5 \% \mathrm{CO}_{2}, 5 \% \mathrm{O}_{2}$ and $90 \% \mathrm{~N}_{2}$. The numbers of embryos at the five- to eight-cell, morula and blastocyst stages on days 3, 7 and 8, respectively, were recorded. Day 7 and day 8 expanded blastocysts developed in SOF-ECS and day 8 blastocysts developed in SOF-BSA or SOF-HA were frozen immediately or allocated for determination of ATP content and number of cells.

\section{Collection of in vivo-derived embryos}

In vivo-derived embryos were recovered as described by Stojkovic et al. (1999b). In brief, German Simmental donor cows were synchronized by one i.m. injection of $500 \mu \mathrm{g}$ $\mathrm{PGF}_{2 \alpha}$ (Estrumate; Mallinckrodt Vet GmbH, Burgwedel) at mid-oestrous cycle. Only cows with a functional corpus luteum on day 8 of the oestrous cycle were superovulated between day 9 and day 14 using 20 iu (NIH) FSH-p (Schering Pharmaceuticals, Kenilworth, NJ). FSH was administered twice each day at a decreasing dosage in a series of eight injections over 4 days. Animals received a double dose of $\mathrm{PGF}_{2 \alpha}$ i.m. at the time of the seventh and the eighth FSH injection and were observed twice each day for signs of oestrus. During oestrus, cows were artificially inseminated (day 0 ) two to three times with frozen-thawed semen from a selected bull of the same breed. After collection, day 7 expanded blastocysts were frozen immediately or allocated for determination of ATP content and number of cells.

\section{Determination of the numbers of inner cell mass (ICM) and trophectoderm (TE) cells of blastocysts}

Equal numbers of embryos (15 expanded blastocysts per treatment group) recovered on day 7 or day 8 after insemi- nation were subjected to differential cell staining as described by Stojkovic et al. (1998a). In brief, blastocysts were washed several times in Dulbecco's PBS to remove excess protein. Blastocysts were treated with $0.5 \%(\mathrm{w} / \mathrm{v})$ pronase (Protease, Type XXV) in PBS for 3-5 min to dissolve the zona pellucida. Subsequently, blastocysts were incubated in a 1:2 dilution in PBS of rabbit antiserum raised against recombinant bovine interferon tau and other trophoblastic secretions (Stojkovic et al., 1997) for $45 \mathrm{~min}$ at $39^{\circ} \mathrm{C}$ in a humidified atmosphere of $5 \% \mathrm{CO}_{2}$ in air. Embryos were then washed five times in PBS warmed at $39^{\circ} \mathrm{C}$, and incubated in PBS supplemented with $5 \%(\mathrm{v} / \mathrm{v})$ guinea-pig complement (ICN Immunobiologicals, Costa Mesa, CA) and $50 \mu \mathrm{g}$ propidium iodide $\mathrm{ml}^{-1}$ for $45 \mathrm{~min}$ at $39^{\circ} \mathrm{C}$ in a humidified atmosphere of $5 \% \mathrm{CO}_{2}$. Blastocysts were then washed in PBS and placed in cold absolute ethanol (Merck, Darmstadt) containing $25 \mu \mathrm{g}$ fluorochrome bisbenzimide $33258 \mathrm{ml}^{-1}$ (Riedel-de Haen AG, Seelze, Hannover) for $30 \mathrm{~min}$ at $4^{\circ} \mathrm{C}$. Finally, embryos were washed in absolute ethanol, mounted in undiluted glycerol (Merck) and squashed on a glass slide. The stained embryos were observed using a fluorescent microscope (Axiovert 135; Zeiss, Jena) with a mercury lamp under transmittance illumination and an UV excitation filter of $365 \mathrm{~nm}$ and a barrier filter of $420 \mathrm{~nm}$.

\section{Freezing-thawing of in vivo-derived and in vitro- produced expanded blastocysts}

Day 7 blastocysts cultured with SOF-ECS and in vivoderived expanded blastocysts, and day 8 expanded blastocysts cultured with SOF-BSA, SOF-HA or SOF-ECS were frozen as described by Stojkovic et al. (1995b). In brief, blastocysts were equilibrated in $1.5 \mathrm{~mol}$ ethylene glycol (EG) $\mathrm{I}^{-1}$ in Emcare TM $^{\mathrm{TM}}$ (ICP, Auckland) medium for $10 \mathrm{~min}$ at room temperature $\left(21^{\circ} \mathrm{C}\right)$, loaded (2-4 embryos per straw) into plastic straws (Minitüb) and placed for $1 \mathrm{~min}$ at $-7^{\circ} \mathrm{C}$ in the freezing machine (Haake, Karlsruhe). After seeding was induced, embryos were cooled at $0.5^{\circ} \mathrm{C} \mathrm{min}^{-1}$ to $-35^{\circ} \mathrm{C}$, after which they were immersed in liquid $\mathrm{N}_{2}$ and stored until use. Embryos were thawed by warming for $10 \mathrm{~s}$ in air at room temperature and $20 \mathrm{~s}$ in a $30^{\circ} \mathrm{C}$ waterbath, washed six times in SOF-ECS medium and then cultured in $400 \mu \mathrm{l}$ SOF-ECS. Re-expansion and hatching rates were evaluated at 24, 48 and $72 \mathrm{~h}$ after thawing. After thawing, expanded blastocysts were used immediately for ultrastructural analysis or determination of ATP content as described below.

\section{Measurement of the ATP content of fresh in vivo-derived and in vitro-produced expanded blastocysts}

The ATP content of both fresh and frozen-thawed in vivo-derived expanded blastocysts or expanded blastocysts developed in SOF medium in the presence of ECS, BSA or $\mathrm{HA}$ was measured using a commercial assay based on the luciferin-luciferase reaction (Bioluminescent Somatic Cell 
Table 1. Mean viscosity and hyaluronic acid (HA) concentration of follicular fluid and different culture media before and after filtration

\begin{tabular}{|c|c|c|c|c|}
\hline \multirow[b]{2}{*}{ Sample } & \multicolumn{2}{|c|}{ Viscosity $\left(\mathrm{mm}^{2} \mathrm{~s}^{-1}\right)$} & \multicolumn{2}{|c|}{$\mathrm{HA}\left(\mu \mathrm{g} \mathrm{I}^{-1}\right)$} \\
\hline & Before filtration & After filtration & Before filtration & After filtration \\
\hline SOF-ECS & $1.25^{\mathrm{a}}$ & $1.13^{\mathrm{ab}}$ & $18.10^{d}$ & $17.40^{d}$ \\
\hline SOF-BSA & $0.99^{a}$ & $0.93^{a}$ & $2.22^{\mathrm{e}}$ & $1.59^{\mathrm{e}}$ \\
\hline SOF-HA & $82.90^{b}$ & $52.03^{c}$ & $5908.33 \times 10^{3 f}$ & $4915.33 \times 10^{3 g}$ \\
\hline Follicular fluid & $4.03^{c}$ & $1.74^{b}$ & $37.19 \times 10^{3 g}$ & $15.87 \times 10^{3 \mathrm{~h}}$ \\
\hline
\end{tabular}

SOF-ECS: synthetic oviduct fluid-oestrous cow serum; SOF-BSA: synthetic oviduct fluid-bovine serum albumin; SOF-HA: synthetic oviduct fluid-hyaluronic acid.

Values with different superscripts ( ${ }^{\mathrm{a}-\mathrm{c}}$ for viscosity; ${ }^{\mathrm{d}-\mathrm{h}}$ for $\mathrm{HA}$ concentration) within columns and rows are significantly different $(P<0.05$; ANOVA followed by Bonferroni post hoc test).

Assay Kit, FL-ASC) according to the technique described by Stojkovic et al. (1999c). Fresh blastocysts (15-21 per treatment) were washed four times in sample buffer $(99.0 \mathrm{mmol}$ $\mathrm{NaCl} \mathrm{I-1}, 3.1 \mathrm{mmol} \mathrm{KCl} \mathrm{I}{ }^{-1}, 0.35 \mathrm{mmol} \mathrm{NaH}_{2} \mathrm{PO}_{4} \mathrm{I}^{-1}$, $21.6 \mathrm{mmol}$ sodium lactate $\mathrm{I}^{-1}, 10.0 \mathrm{mmol}$ Hepes $\mathrm{I}^{-1}$, $2.0 \mathrm{mmol} \mathrm{CaCl}_{2} \mathrm{I}^{-1}, 1.1 \mathrm{mmol} \mathrm{MgCl}_{2} \mathrm{I}^{-1}, 25.0 \mathrm{mmol}$ $\mathrm{NaHCO}_{3} \mathrm{I}^{-1}, 1.0 \mathrm{mmol}$ sodium pyruvate $\mathrm{I}^{-1}, 0.1 \mathrm{mg}$ gentamicin $\mathrm{ml}^{-1}$ and $6.3 \mathrm{mg}$ BSA $\mathrm{ml}^{-1}$ ). Embryos were transferred individually in $50 \mu$ l of sample buffer and placed into separate plastic tubes, which were transferred into iced water. Subsequently, $50 \mu \mathrm{l}$ ice-cold somatic cell reagent (FL-SAR) was added to each tube and tubes were held in iced water for $5 \mathrm{~min}$. After this procedure, $100 \mu \mathrm{l}$ ice-cold assay mix (FL-AAM) (diluted 1:25 with ATP Assay Mix Dilution Buffer, FL-AAB) was added and the tubes were held for $5 \mathrm{~min}$ at room temperature in the dark. After thawing, groups of 10-12 (in total 52-63 embryos) in vivoderived and in vitro-produced expanded blastocysts were cultured in $400 \mu \mathrm{l}$ SOF-ECS. The ATP content of frozenthawed expanded blastocysts was measured at 0.0, 0.5, 1.0, 3.0 and $6.0 \mathrm{~h}$ after thawing. The ATP content of the samples was measured individually using a luminometer (Bioluminat Junior; Berthold, Wildbad). A seven point standard curve (0-6 pmol tube ${ }^{-1}$ ) was routinely included in each assay. The ATP content was determined from the formula for the standard curve.

\section{Semithin sections and transmission electron microscopy}

The effects of culture condition on ultrastructure of embryos was investigated by removing 20 day 8 expanded blastocysts cultured with SOF-BSA and 21 day 8 expanded blastocysts cultured with SOF-HA from the culture medium. The blastocysts were washed in cacodylate buffer (0.2 mmol sodium cacodylate $\left.\mathrm{I}^{-1}, \mathrm{pH} 7.2\right)$ and fixed in Karnovsky's fluid (2.5\% (v/v) glutaraldehyde and 2\% (v/v) formaldehyde in $0.1 \mathrm{~mol}$ cacodylate buffer $\mathrm{I}^{-1}$ ). Embryos were then fixed in $1 \%(\mathrm{w} / \mathrm{v}) \mathrm{OsO}_{4}$ and $1.5 \%(\mathrm{w} / \mathrm{v}) \mathrm{KFe}(\mathrm{CN})_{6}$ and transferred to a drop of $20 \%(\mathrm{w} / \mathrm{v}) \mathrm{BSA}$ in cacodylate buffer. The addition of $25 \%(\mathrm{v} / \mathrm{v})$ glutaraldehyde resulted in the polymerization of BSA to a pellet containing the embryo. The pellet was dehydrated in a graded series of ethanol and embedded in Epon (Polysciences, Eppelheim). Semithin sections $(1 \mu \mathrm{m})$ were cut and stained with methylene blue to assess the cellular compartments of the embryos. Ultrathin sections $(50 \mathrm{~nm})$ were mounted on grids, stained with $\mathrm{OsO}_{4}$ and examined under a Zeiss electron microscope.

\section{Statistical analysis}

The rates of early cleavage stage embryo, morula and blastocyst development and survival after cryopreservation were evaluated using the binomial model and Logit Link by general linear mixed models procedure (GLIMMIX, SAS, version 6.12; SAS Institute, Inc., Cary, NC). The general linear model (GLM) was used to estimate fixed effects of culture condition and age of embryos, and interactions between these factors on the re-expansion, hatching and total survival rates of frozen-thawed embryos. When a significant $(P<0.05) \quad F$ value was found, the GLM procedure was used to calculate least squares means, which were compared with $t$ tests. The numbers of ICM and TE cells and the total number of cells were compared using Mann-Whitney $U$ test. When an $F$ value was significant $(P<0.05)$, HA concentration of follicular fluid and the various culture media, as well as ATP contents of fresh and frozen-thawed blastocysts, were compared using ANOVA followed by Bonferroni post hoc test. Differences were considered significant at $P<0.05$.

\section{Results}

\section{Viscosity of used culture media}

The mean viscosities of follicular fluid and SOF medium with different supplements (ECS, BSA, HA) are presented (Table 1). HA significantly $(P<0.001)$ increased the viscosity of culture medium when compared with other samples measured. Follicular fluid had a higher viscosity than SOF-BSA and SOF-ECS media, but only the difference between follicular fluid and SOF-BSA was significant $(P<0.05)$. 


\section{Concentration of HA in follicular fluid and culture media}

Before filtration, concentrations of $\mathrm{HA}$ in SOF-ECS $\left(18.10 \pm 0.18 \mu \mathrm{g} \mathrm{HA} \quad I^{-1}\right)$ were significantly $(P<0.05)$ higher than those in SOF-BSA $\left(2.22 \pm 0.01 \mu \mathrm{g} \mathrm{HA}{ }^{-1}\right)$ (Table 1). Within non-filtered groups, significantly $(P<$ $0.001)$ more HA was present in SOF-HA medium than in follicular fluid, SOF-BSA and SOF-ECS media. The same finding was observed after filtration of samples. The concentration of HA in filtered samples was always lower compared with non-filtrated samples, but the differences were significant $(P<0.05)$ only for the SOF-HA and follicular fluid samples.

\section{Cleavage and rates of blastocyst development}

Early cleavage rate (embryos with five- to eight-cells on day 3 after insemination) was significantly $(P<0.05)$ higher in embryos cultured with SOF-BSA than with SOF-ECS $(73.8 \pm 2.4$ versus $66.9 \pm 3.6)$ (Table 2$)$. On day 7 , significantly $(P<0.05)$ more morulae developed in SOF-HA medium than in SOF-ECS or SOF-BSA medium. However, on day 7 , significantly $(P<0.01)$ more blastocysts developed in SOF-ECS than in SOF-HA or SOF-BSA medium. On day 7 , total embryo rate in SOF-HA tended to be higher than in SOF-BSA $(35.6 \pm 2.8$ versus $31.0 \pm 1.5)$. This difference was significant $(P<0.05)$ in day 8 embryos $(38.2 \pm 3.4$ versus $29.3 \pm 2.1)$. The highest total development rate on either day 7 or day 8 was obtained using SOF-ECS (Table 2).

\section{Differential staining of ICM and TE cells}

Day 7 in vivo-derived expanded blastocysts possessed more ICM cells (48.4 \pm 0.6 ; Fig. 1a) than did day 7 expanded blastocysts cultured with SOF-ECS (45.6 \pm 2.4$)$ and day 8 expanded blastocysts cultured with SOF-ECS $(40.3 \pm 1.4)$, SOF-BSA (37.2 \pm 1.4$)$ or SOF-HA (41.2 \pm 4.5$)$. Expanded blastocysts cultured in the presence of $\mathrm{HA}$ possessed more ICM cells than did other embryos cultured in vitro, but the differences were not significant. However, HA significantly $(P<0.01)$ increased the number of TE cells (Fig. 1b) and the total numbers of cells (Fig. 1c) compared with expanded blastocysts cultured in the presence of BSA $(88.9 \pm 7.3$ versus $67.6 \pm 3.0$ and $130.1 \pm 10.9$ versus $104.8 \pm 2.5$, respectively). The addition of $\mathrm{HA}$ to the culture medium consistently increased the number of TE cells and the total number of cells, which were similar to those of in vivo-derived embryos.

\section{ATP content of in vivo-derived and in vitro-produced bovine embryos}

Fresh day 8 expanded blastocysts cultured in the presence of ECS contained significantly $(P<0.01)$ more ATP $(2.34 \pm 0.25$ pmol $)$ than did day 7 expanded blastocysts $(1.21 \pm 0.08 \mathrm{pmol})$ cultured under the same conditions, day 8 blastocysts cultured with SOF-BSA (0.75 \pm $0.06 \mathrm{pmol})$ or SOF-HA $(0.61 \pm 0.04 \mathrm{pmol})$ and day 7 in vivo-derived expanded blastocysts $(1.05 \pm 0.07$ pmol). However, in vivo-derived expanded blastocysts contained significantly $(P<0.05)$ more ATP than expanded blastocysts developed in the presence of BSA or HA (Fig. 2).

\section{Effects of culture conditions and age of frozen-thawed blastocysts on the re-expansion, hatching and total survival rates}

The percentages of day 8 embryos re-expanding and hatching, and the total number of embryos that continued to develop (that is, sum of embryos re-expanding and hatching) were affected by culture condition. The effects of embryo age and the interaction of culture condition $\times$ age were not significant and were omitted from the model. By $24 \mathrm{~h}$ of culture after thawing, the total percentage of embryos that continued to develop was significantly $(F=4.75, P<0.01)$ affected by culture conditions, with a lower performance of frozen-thawed embryos developed in SOF-BSA than embryos in the other two culture groups (which behaved similarly). This effect continued after extended culture to 48 and 72 h. Comparison between SOF-ECS embryos frozen on day 7 or day 8 revealed that day 8 embryos appeared to tolerate freezing and thawing better than day 7 embryos (Table 3).

In vivo-derived embryos, and day 8 blastocysts cultured with SOF-ECS and SOF-HA all behaved in a similar way after thawing (Table 3).

\section{ATP content of frozen-thawed in vivo-derived and in vitro-produced bovine embryos}

After thawing, day 8 expanded blastocysts cultured with ECS contained significantly $(P<0.01)$ more ATP than did day 7 SOF-ECS, in vivo-derived or SOF-BSA and SOF-HA expanded blastocysts (Fig. 3). The same tendency was observed after 1, 3 and $6 \mathrm{~h}$, except that after $6 \mathrm{~h}$ the ATP content of day 7 blastocysts cultured with SOF-ECS was also significantly $(P<0.001)$ higher than that of blastocysts cultured with SOF-BSA or SOF-HA or of in vivo-derived blastocysts. The ATP contents of in vivo-derived, and SOF-HA and SOF-BSA expanded blastocysts were similar.

\section{Semithin sections and transmission electron microscopy of fresh and frozen-thawed 8-day-old embryos cultured with SOF-BSA or SOF-HA}

The 8-day-old embryos cultured with SOF-BSA showed a clear differentiation of TE and ICM cells surrounding a blastocoel. Although the polyhedral ICM cells had a spherical nucleus with large nucleoli, the flattened trophoblast cells were characterized by an oval nucleus and occasional mitotic figures. The microvilli of the apical membrane of the trophoblast cells were well developed. The most conspicuous and abundant organelles were mitochondria of different sizes characterized by a round or elongated shape and transverse cristae (Fig. 4a). Embryos cultured with SOF-BSA had Golgi apparatus and numerous ballooned 


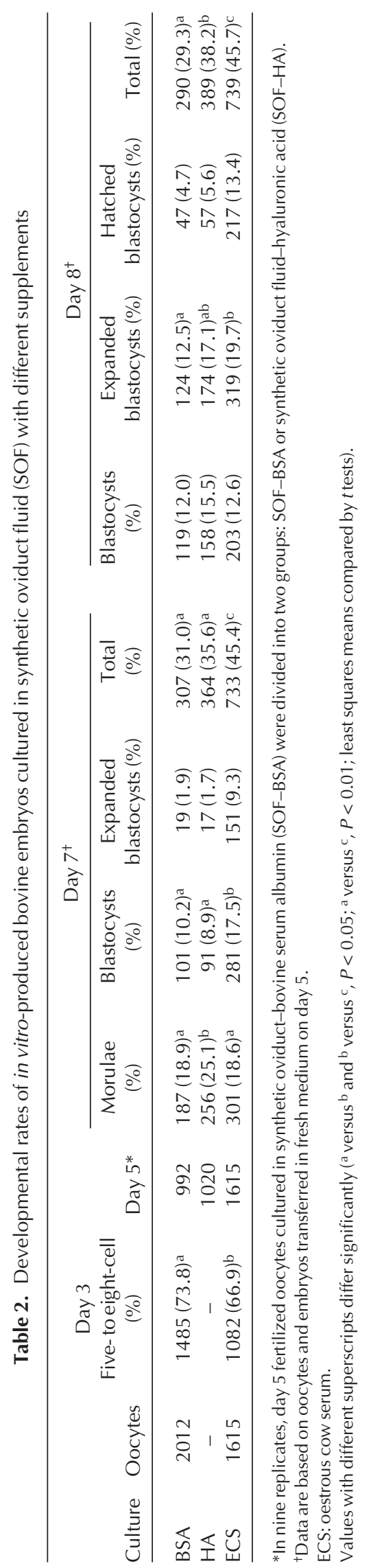



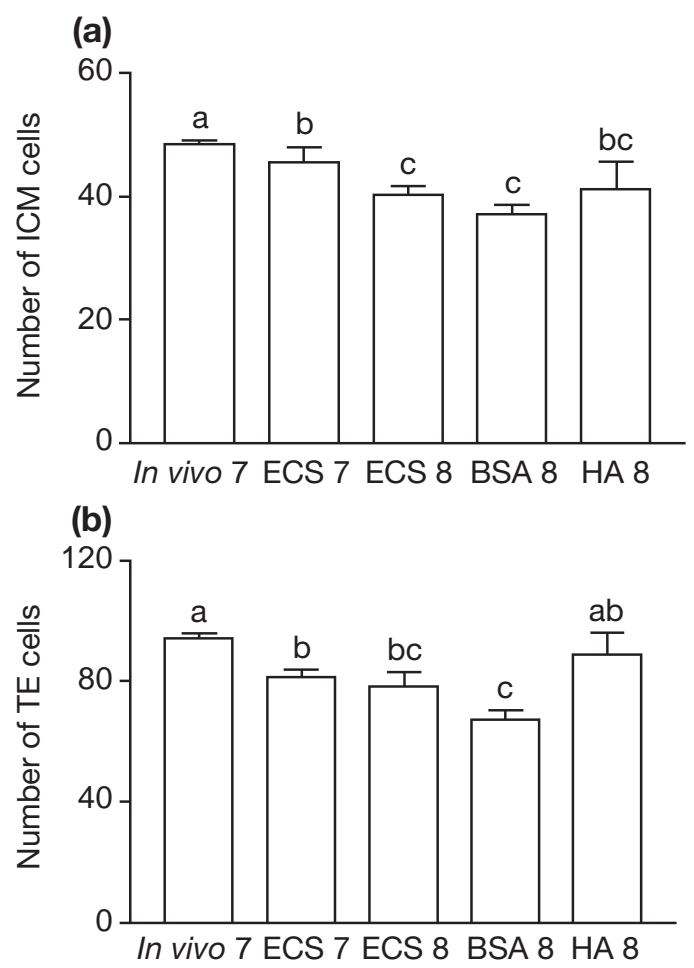

$$
\text { (c) }
$$

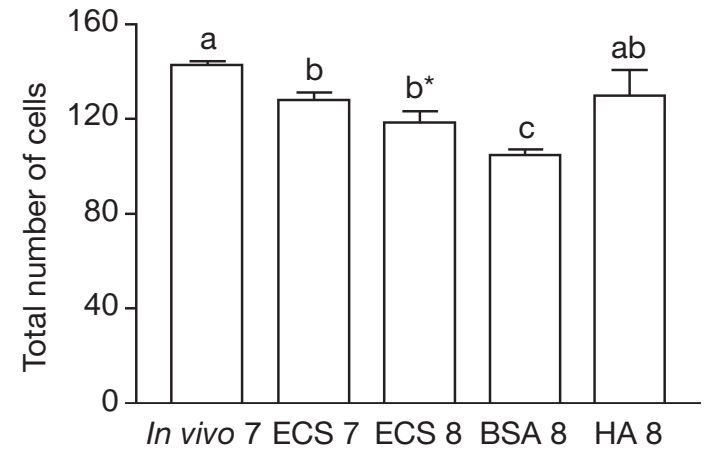

Fig. 1. The effect of hyaluronic acid (HA) supplementation on the number of (a) inner cell mass (ICM) cells, (b) trophectoderm (TE) cells and (c) the total number of cells of bovine embryos produced in vitro. Data are presented as mean \pm SEM (error bars) from 15 expanded blastocysts analysed per experimental group. ${ }^{\text {a-c Within }}$ each graph, bars with different superscripts are significantly different $(P<0.05) ; * P=0.06$ oestrous cow serum (ECS) 7 versus ECS 8 (Mann-Whitney $U$ test). In vivo 7 : day 7 in vivo-derived embryos; ECS 7: day 7 embryos cultured with ECS; ECS 8: day 8 embryos cultured with ECS; BSA 8: day 8 embryos cultured with BSA; HA: day 8 embryos cultured with HA.

rough endoplasmatic reticulae, implying high rates of protein synthesis (Fig. 4a). In the embryonic cells, numerous lysosomes and lipid vacuoles were visible. Cell debris accumulated regularly in the ICM (Fig. 4a) and TE cells, and between the trophoblast cells and the zona pellucida.

In a similar manner to the embryos cultured with BSA, embryos treated with $\mathrm{HA}$ revealed a differentiation in trophoblast cells and ICM. However, in the embryos

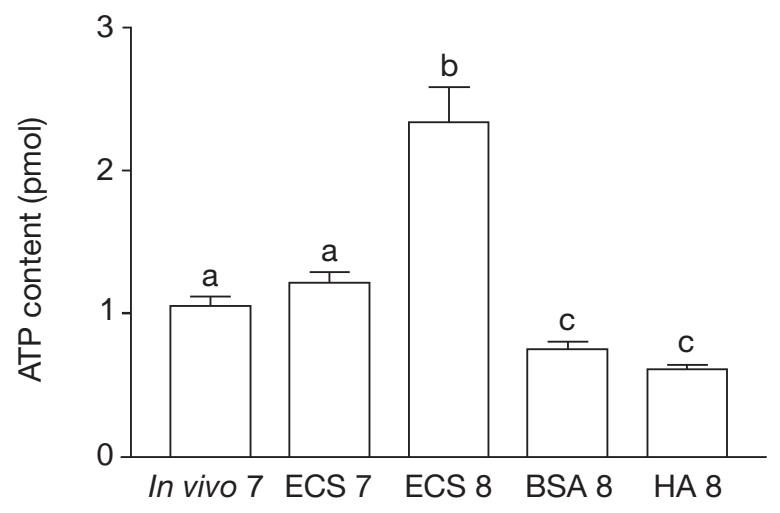

Fig. 2. ATP content of fresh in vivo-derived and in vitro-produced bovine embryos cultured with different supplements. Data are presented as the mean \pm SEM from 15 expanded blastocysts analysed per experimental group. ${ }^{\mathrm{a}-\mathrm{c} B a r s}$ with different superscripts are significantly different $(P<0.05$; ANOVA followed by Bonferroni post hoc test). In vivo 7: day 7 in vivo-derived embryos; ECS 7: day 7 embryos cultured with oestrous cow serum (ECS); ECS 8: day 8 embryos cultured with ECS; BSA 8: day 8 embryos cultured with BSA; HA 8: day 8 embryos cultured with hyaluronic acid.

cultured with $\mathrm{HA}$, the blastocoel was distinctly smaller than in the embryos cultured with BSA, implying a slower formation of the blastocoel in these embryos. The number of organelles in the cytoplasm of the embryonic cells seemed to be increased in embryos cultured with HA compared with those cultured in BSA. Marked differences were seen in the morphology of the mitochondria. Although mitochondria of embryos cultured with BSA were of the typical hooded appearance (Fig. 4a), embryos cultured with $\mathrm{HA}$ showed exclusively mitochondria with very few cristae or mitochondria with ballooned cristae (Fig. 4b). Further differences between the two groups of embryos were seen in the formation of lysosome-like structures and in the accumulation of cell debris, which was distinctly greater in embryos cultured with HA (Fig. 4b). Microvilli seemed to be more abundant in embryos cultured with HA compared with embryos cultured with BSA (Fig. 4c)

Cryopreservation resulted in distinct morphological alterations in both groups of embryo. The most conspicuous alteration was extended vacuolization of the cytoplasm of the embryonic cells and the formation of large intercellular cracks (Figs 5 and $6 a$ ). The number of cell organelles was distinctly reduced in both groups (Fig. 6a). The accumulation of cell debris was markedly increased (Fig. 6a). The nuclei of the embryonic cells were often irregular in shape and only rarely was heterochromatin detected (Fig. 5a,b). Generally, embryonic cells revealed irregular forms and showed signs of deviation; the differentiation in trophoblast and ICM cells was no longer visible (Fig. 5a,b).

In general, the embryos cultured with HA showed less deviation after freezing than did embryos cultured with BSA. In HA embryos, morphologically intact cells could be detected (Fig. 6b), which was not possible in BSA embryos. 
Table 3. Re-expansion and hatching of frozen-thawed bovine blastocysts produced in vitro

\begin{tabular}{|c|c|c|c|c|c|c|c|c|c|c|}
\hline \multirow[b]{2}{*}{ Culture (day) } & \multirow[b]{2}{*}{$n^{*}$} & \multicolumn{3}{|c|}{$24 \mathrm{~h}$} & \multicolumn{3}{|c|}{$48 \mathrm{~h}$} & \multicolumn{3}{|c|}{$72 \mathrm{~h}$} \\
\hline & & $\begin{array}{c}\text { Re-expansion } \\
(\%)\end{array}$ & $\begin{array}{c}\text { Hatching } \\
(\%)\end{array}$ & $\begin{array}{l}\text { Total } \\
(\%)\end{array}$ & $\begin{array}{c}\text { Re-expansion } \\
(\%)\end{array}$ & $\begin{array}{l}\text { Hatching } \\
(\%)\end{array}$ & $\begin{array}{l}\text { Total } \\
(\%)\end{array}$ & $\begin{array}{c}\text { Re-expansion } \\
(\%)\end{array}$ & $\begin{array}{c}\text { n Hatching } \\
(\%)\end{array}$ & $\begin{array}{c}\text { Total } \\
(\%)\end{array}$ \\
\hline In vivo (7) & 37 & $23(62.2)^{\mathrm{a}}$ & $6(16.2)^{\mathrm{ab}}$ & $29(78$ & $9(2$ & $24(64.9)^{\mathrm{a}}$ & $33(89.2)^{\mathrm{a}}$ & $4(10$ & $30(81.1)^{\mathrm{a}}$ & $34(91.9)^{\mathrm{a}}$ \\
\hline SOF-ECS (7) & 49 & $11(22.4)^{b}$ & $15(30.6)^{\mathrm{a}}$ & $26(53.1)^{\mathrm{bc}}$ & $13(26.5)$ & $15(30.6)^{b+}$ & $28(57.1)^{b c}$ & $0(0)$ & $27(55.1)^{\mathrm{bc}}$ & $27(55.1)^{b}$ \\
\hline SOF-ECS (8) & 45 & $27(60.0)^{\mathrm{a}}$ & $6(13.3)^{a b}$ & $33(73.3)^{\mathrm{ac}}$ & $9(20.0)$ & $25(55.6)^{\mathrm{ab}}$ & $34(75.6)^{\mathrm{ab}}$ & $1(2.2)$ & $31(68.9)^{\mathrm{ab}}$ & $32(71.1)^{\mathrm{ab} \neq}$ \\
\hline SOF-BSA (8) & 57 & $19(33.3)^{b}$ & $2(3.5)^{\mathrm{b}}$ & $21(36.8)^{b}$ & $12(21.0)$ & $17(29.8)^{b}$ & $29(50.8)^{c}$ & $6(10.5)$ & $21(36.8)^{\mathrm{c}}$ & $27(47.3)^{b}$ \\
\hline SOF-HA (8) & 53 & $32(60.4)^{\mathrm{a}}$ & $5(9.5)^{b}$ & $37(69.8)^{\mathrm{ac}}$ & $13(24.5)$ & $33(62.2)^{\mathrm{a}}$ & $46(86.7)^{a}$ & $6(11.3)$ & $40(75.5)^{\mathrm{a}}$ & $46(86.8)^{\mathrm{a}}$ \\
\hline
\end{tabular}

*All embryos that were frozen in 1.5 mol ethylene glycol $\mathrm{I}^{-1}$ were recovered after thawing.

In four replicates, two to four expanded blastocysts from the in vivo group, the synthetic oviduct fluid-oestrous cow serum (SOF-ECS) day 7 group, SOF-ECS day 8 group, the synthetic oviduct fluid-bovine serum albumin (SOF-BSA) group, and synthetic oviduct fluid-hyaluronic acid (SOF-HA) group were loaded per straw into $10,13,12,15$ or 14 straws, respectively.

${ }^{+}$SOF-ECS day 7 versus SOF-ECS day $8, P=0.07 ;{ }^{\ddagger}$ SOF-ECS day 8 versus SOF-BSA, $P=0.06$.

Values with different superscripts within columns differ significantly (a versus ${ }^{b}, P<0.05$ and ${ }^{a}$ versus ${ }^{c}, P<0.01$; least squares means compared by $t$ tests).

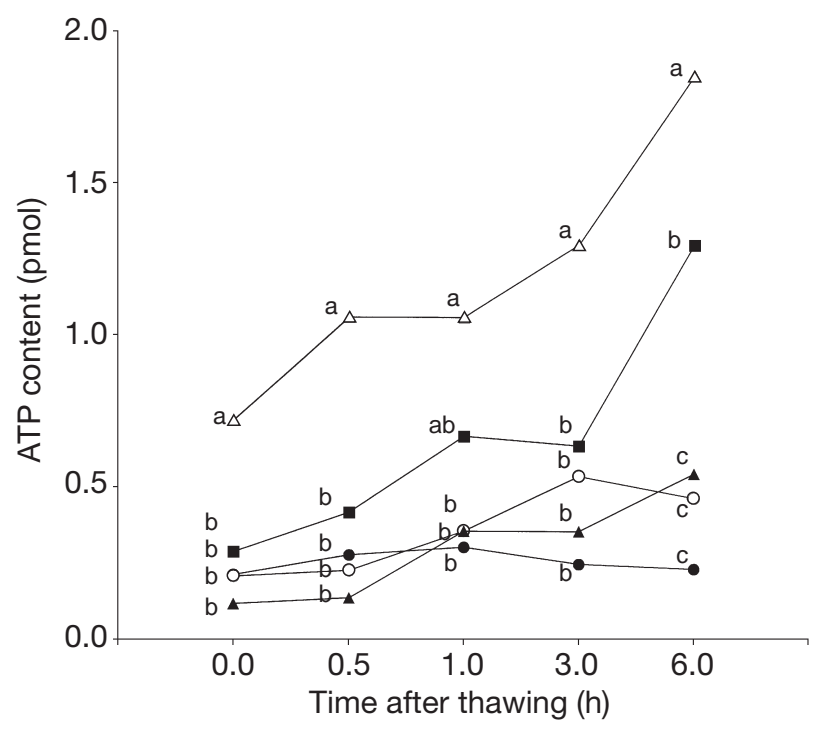

Fig. 3. Comparison of the ATP contents of frozen-thawed in vivoderived and in vitro-produced bovine embryos measured at different time points after cryopreservation. Mean values from 10-12 expanded blastocysts were analysed between different culture treatments using ANOVA followed by Bonferroni post hoc test $(P<0.05)$. $(\mathbf{O})$ : Day 7 in vivo-derived embryos; $(\square)$ : day 7 embryos cultured with oestrous cow serum $(E C S) ;(\triangle)$ : day 8 embryos cultured with ECS; $(\mathbf{\Delta})$ : day 8 embryos cultured with BSA; $(\bigcirc)$ : day 8 embryos cultured with hyaluronic acid. a versus b, $P<0.01 ;{ }^{\mathrm{a}}$ versus ${ }^{\mathrm{c}}$ and ${ }^{\mathrm{b}}$ versus $^{\mathrm{c}}, P<0.001$.

Embryos cultured with BSA showed not only irregular, deviated cells, but also large areas of cytoplasm without any organelles (Fig. 6a). The cells of the embryos cultured with BSA always lost contact with the zona pellucida after freezing (Fig. 5a), a phenomenon which was not seen in embryos cultured with HA (Fig. 5b). Lysosome-like structures in the cells and accumulation of cell debris were seen more frequently in embryos cultured with BSA than in embryos cultured with HA (Fig. 6a). Similar to the fresh embryos, after freezing, the microvilli in embryos cultured with HA seemed more prominent and dense than in embryos cultured with BSA.

\section{Discussion}

In the present study, the effects of the high concentrations of HA on early embryonic development and sensitivity to cryopreservation of in vitro-derived bovine blastocysts were evaluated.

The viscosity of the basic medium used (synthetic oviduct fluid) was markedly increased after the addition of $\mathrm{HA}$ in both non-filtered and filtered samples. To our knowledge there are no studies that describe the viscosity of bovine oviduct and uterine fluid. Bovine embryos are able to develop to the blastocyst stage in highly viscous medium supplemented with Guar Gum (Stojkovic et al., 1998b) or hydroxypropylmethylcellulose (M. Stojkovic, unpublished) and with HA (Stojkovic et al., 1999a; this study). The viscosity of $\mathrm{HA}$ solutions varies with molecular weight and concentration. The commercially available material has molecular weights ranging from $<1 \times 10^{6}$ to as much as $8 \times 10^{6}$, and this certainly influences the biological and physicochemical properties of HA. In addition, our preliminary results demonstrate that the origin of $\mathrm{HA}$ (human umbilical cord, rooster comb or Streptococcus equi sp.) influences bovine embryo development in vitro (data not presented). In the present study, a high concentration of HA (molecular weight: $1.69 \times 10^{6}$ ) was used to increase the viscosity of culture medium.

Marquant-Le Guienne et al. (1998) demonstrated that HA can successfully substitute for sera for in vitro maturation of bovine oocytes. In support of the results from the present study, Stojkovic et al. (1999a) and several other studies have demonstrated that supplementation of culture medium with HA improves in vitro development of bovine (Furnus et al., 1998) and pig (Miyoshi et al., 1999) embryos 

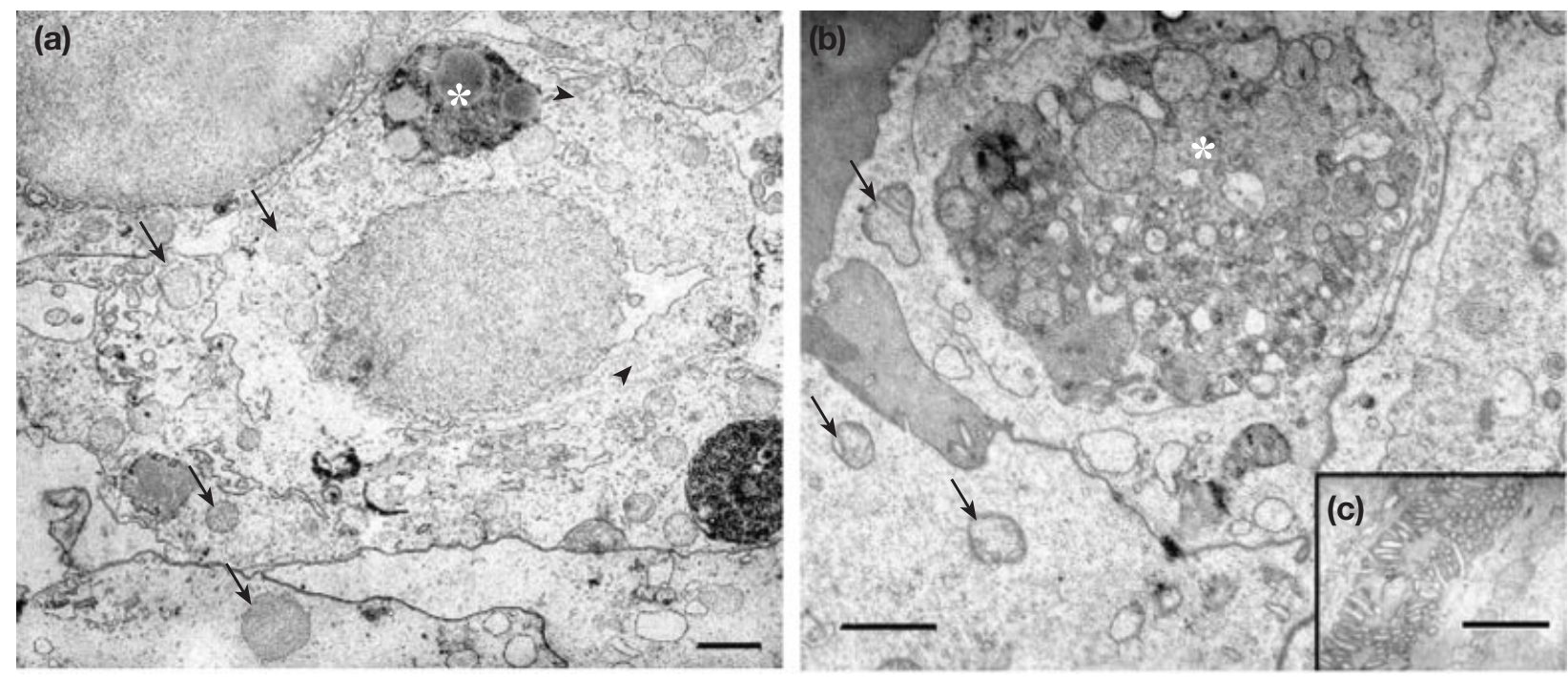

Fig. 4. Ultrastructure of 8-day-old expanded bovine blastocysts cultured with (a) synthetic oviduct fluid-bovine serum albumin (SOF-BSA) or (b,c) synthetic oviduct fluid-hyaluronic acid (SOF-HA). The inner cell mass cells of embryos cultured with BSA possess ballooned endoplasmic reticulum implying high protein synthesis (arrowhead). In addition, (a) embryos cultured with BSA have mitochondria with the typical hooded appearance (arrows), whereas (b) embryos cultured with HA show exclusively mitochondria with very few cristae or mitochondria with ballooned cristae (arrows). The accumulation of cell debris $(*)$ is distinctly increased in (b) embryos cultured with HA compared with (a) embryos cultured with BSA. Microvilli seem to be more abundant in embryos cultured with (c) HA as compared with embryos cultured with BSA. Scale bars represent $2 \mu \mathrm{m}$.

up to the blastocyst stage. In mice, increased rates of implantation and fetal development after blastocyst transfers were observed when $\mathrm{HA}$ was added to the culture medium (Gardner et al., 1999).

In the present study, blastocysts cultured in the presence of HA contained a similar total number of cells to in vivoderived embryos. There was an increase in the number of TE cells of embryos cultured with SOF-HA in comparison to embryos cultured in the presence of BSA, demonstrating that HA plays an important role in cell proliferation. Induction of proliferation by $\mathrm{HA}$ has been widely demonstrated in regenerating or healing tissues (Laurent, 1992). HA is also involved in cell migration and proliferation, critical events in tissue remodelling during development, morphogenesis and normal tissue homeostasis (Toole, 1997). In mice, HA plays a crucial role in the attachment of the blastocyst and outgrowth of the trophectoderm, markedly promoting the differentiation of extraembryonic structures of the embryo (Hamashima, 1982). The absence of HA leads to the gradual degeneration and loss of ICM cells and to the end of cell proliferation of primary trophoblast giant cells (Hamashima, 1982).

The interaction of HA with matrix HABPs (hyaladherins) and cell surface HA receptors (CD44) regulates not only cell behaviour, such as cell migration, cell to cell adhesion, cell differentiation and proliferation, but also plays a role in cell metabolism. After endocytosis, HA is transported to lysosomes, degraded to glucuronic acid and $\mathrm{N}$ - (a)

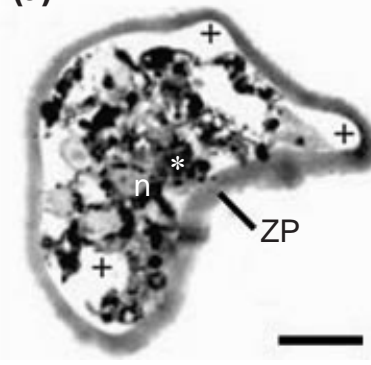

(b)

Fig. 5. Semithin sections of frozen-thawed 8-day-old bovine expanded blastocysts developed in (a) synthetic oviduct fluidbovine serum albumin (SOF-BSA) or (b) synthetic oviducthyaluronic acid (SOF-HA). The cells of the embryos cultured with BSA always lose contact (+) with the zona pellucida after freezing (a); however, this is not the case in embryos cultured with HA (b). ZP: zona pellucida; n: nuclei; *lipid vacuoles. Scale bars represent $50 \mu \mathrm{m}$.

acetylglucosamine. These monosaccharides are transferred to the cytosol, where the glucuronic acid is degraded via its regular pathway. $\mathrm{N}$-acetylglucosamine becomes phosphorylated to $\mathrm{N}$-acetylglucosamine 6-phosphate, which can be deaminated to fructose 6-phosphate, a glycolytic substrate (Laurent, 1992). The mechanism by which HA influences embryonic metabolism is not clear, but in the plasma membrane of cells from the rat liver, HA reduces 

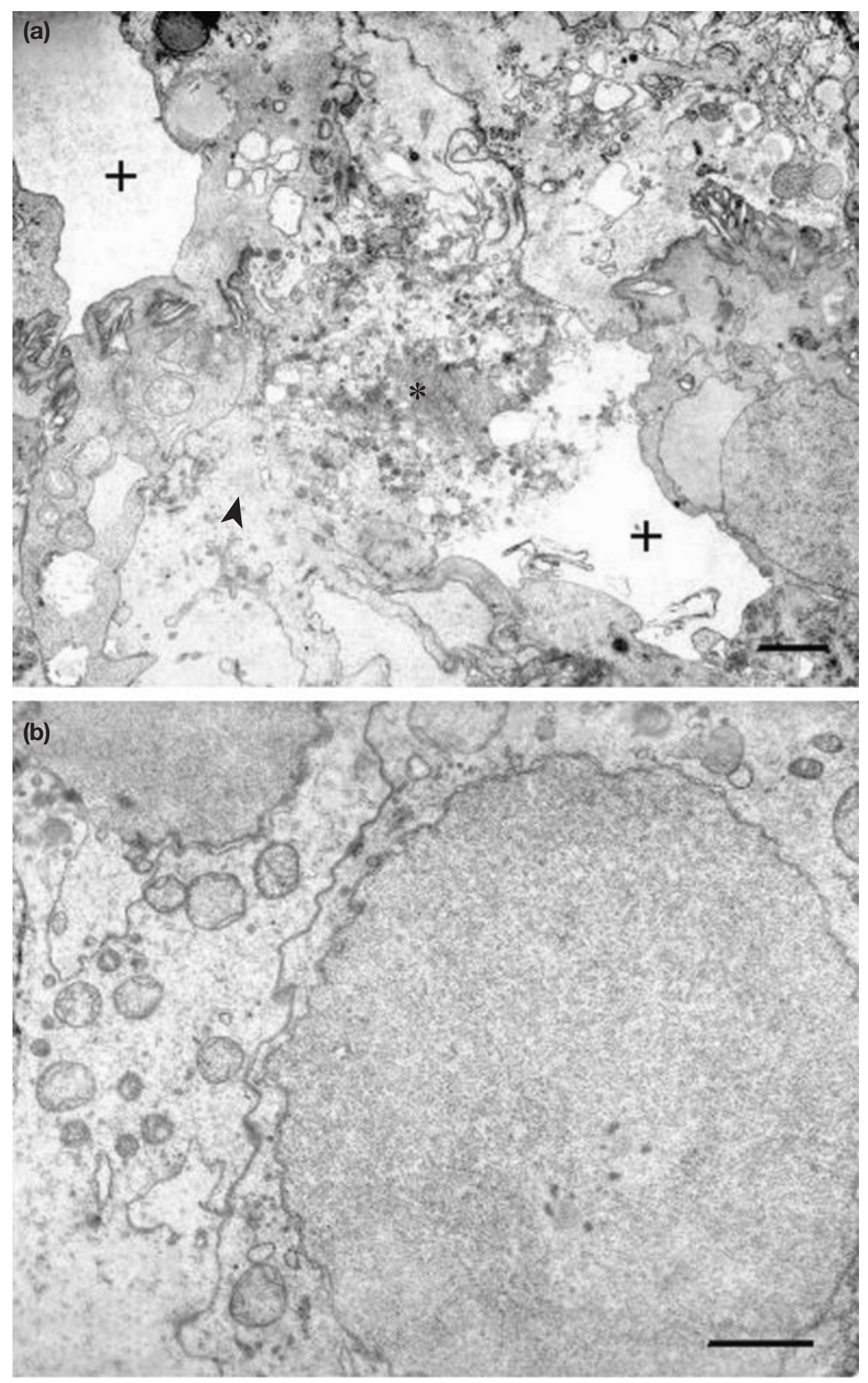

Fig. 6. Ultrastructure of frozen 8-day-old expanded bovine blastocysts cultured with (a) synthetic oviduct fluid-bovine serum albumin (SOF-BSA) or (b) synthetic oviduct fluid-hyaluronic acid (SOF-HA) immediately after thawing. Cryopreservation of embryos cultured with BSA results in extended vacuolization of the cytoplasm of the embryonic cells and the formation of large intercellular spaces $(+)$. The accumulation of cell debris $\left(^{*}\right)$ is markedly increased. There are wide areas of cytoplasm without organelles (arrowhead). Embryonic cells reveal irregular forms and show signs of deviation. In contrast to the (a) embryos cultured with BSA, (b) embryos cultured with HA possess morphologically intact cells. Scale bars represent $2 \mu \mathrm{m}$. 
adenylate cyclase activity, which is necessary for maintaining ATP concentrations (Dittmann et al., 1998). In the present study, embryos cultured with SOF-HA or SOF-BSA and in vivo-recovered embryos contained less total ATP than did embryos cultured with SOF-ECS. The possible explanations for these findings are: (i) impaired enzymatic conversion of ATP due to the reduced adenylate cyclase activity in the presence of HA; (ii) developmental status and density of mitochondria; and (iii) high ATP content of blastocysts developed in medium with serum could be attributable to broad metabolic disturbances in ATP degradation and carriers of energy. An increased accumulation of ATP in bovine embryos could be a sign of poor metabolic turnover, that is, stress and non-functional biosynthesis and cellular activity. It was suggested that mouse embryos with high ATP content had low ATP synthesis, and decreased nucleic acid and protein synthesis (Ginsberg and Hillman, 1973).

After thawing, ATP content was low but then increased in all in vitro-produced groups, and reached a peak similar to that observed in fresh in vitro-produced embryos after 3-6 h. This finding demonstrates that in vitro-produced and cryopreserved embryos require some time to recover and to reach the ATP content of fresh embryos. These data are in agreement with the studies reported by Vajta et al. (1997), which demonstrated that in vitro-produced bovine embryos require at least $4 \mathrm{~h}$ to regenerate and reorganize damaged ultrastructural configuration after cryopreservation. In the present study, in vivo-derived frozen-thawed embryos do not completely reach the ATP content of fresh embryos. This finding could be caused by the in vitro culture conditions used after thawing of in vivo-derived embryos. It is important to state that the ATP curves of SOF-BSA and SOF-HA embryos at different measurement times were synchronized with in vivo-recovered frozen-thawed embryos, indicating that serum-free embryos are metabolically more similar to in vivo-derived embryos than embryos recovered in the presence of serum. Embryos cultured with SOF-BSA showed low rates of development after thawing. The addition of HA to the culture medium significantly increased survival of embryos after thawing, and therefore $\mathrm{HA}$ is warranted as a supplement for in vitro production of bovine embryos, particularly for those embryos that are to be cryopreserved. Further studies are necessary to confirm the improved viability of in vitro-produced bovine embryos cultured in the presence of HA by embryo transfer.

Palasz et al. $(1993,2000)$ demonstrated that the presence of HA in the freezing medium increases survival of frozenthawed bovine blastocysts. These authors postulated that this may be due to a reduced toxicity of cryoprotectant by $\mathrm{HA}$. It is possible that the high water binding capacity of $\mathrm{HA}$ increased not only viscoelastic properties of the culture medium, but also cytosolic viscosity of embryos, which may bolster cell survival by decreasing the growth of lethal intracellular ice crystals (Stojkovic et al., 2001c). Introduction of intracellular trehalose improves the survival of cryopreserved mammalian cells in a similar way: increasing cytosolic viscosity and decreasing the growth of lethal intracellular ice crystals (Eroglu et al., 2000). Similarly, plants synthesize oligosaccharides of the raffinose family in response to low temperature (Crowe and Crowe, 2000). The accumulation of oligosaccharides of the raffinose family is believed to play an important role in the stabilization of structures and function of cellular liquids and the freezing tolerance. Again, HA has strong water-binding capacity, the ability to interact with water to obtain a gel-like structure and, hence, the ability to reduce water mobility. It is highly likely that HA decreases the lethal consequences of crystallization and, at the same time, increases the resistance of membranes and organelles to the shock of cryopreservation. This finding is confirmed by our ultrastructural studies in which HA was demonstrated to reduce the extent of cellular damage caused by cryopreservation. Thus, the vacuolization of the embryonic cells, the degradation of cell organelles and the formation of intercellular spaces after cryopreservation were markedly reduced by the addition of $\mathrm{HA}$ to the culture medium. In embryos cultured with SOF-HA, morphologically intact cells were observed after cryopreservation; this was not observed in the SOF-BSA embryos. The presence of dense and prominent microvilli in the embryos cultured with SOF-HA indicates the preservation of metabolic activity in these embryos. Although the mitochondria of embryos cultured in the presence of HA had very few cristae or even ballooned cristae, the ATP content was not significantly altered in these embryos as compared with control (BSA) embryos. These results indicate that the morphology of mitochondria is clearly influenced by culture conditions and origin of the embryos (Abe et al., 1999; Crosier et al., 2000; Fair et al., 2001), but that mitochondrial morphology does not necessarily affect energy metabolism.

In summary, the results from the present study demonstrate that a high concentration of $\mathrm{HA}$ increases the viscosity of culture medium and improves in vitro development and the number of cells of bovine embryos. The survival rate after freezing of embryos cultured with HA supplementation before freezing was also increased. HA probably affects the development, proliferation, vitality and ultrastructure of in vitro-produced bovine embryos via different pathways acting through its complex chemical and physical properties. Further studies are necessary to explain the molecular mechanism and biological-physiological roles of $\mathrm{HA}$ in early bovine embryogenesis.

The authors are grateful to A. Koppi from the Fraunhofer Institute in Munich for the measurements of viscosity. This study was supported by grants from the Bayerische Forschungsstiftung and from the Deutsche Forschungsgemeinschaft.

\section{References}

Abe H, Yamashita S, Itoh T, Satoh T and Hoshi H (1999) Ultrastructure of bovine embryos developed from in vitro-matured and -fertilized oocytes: comparative morphological evaluation of embryos cultured 
either in serum-free medium or in serum-supplemented medium Molecular Reproduction and Development 53 325-335

Bavister BD (1995) Culture of preimplantation embryos: facts and artifacts Human Reproduction Update 191-148

Campbell S, Swann HR, Aplin JD, Seif MW, Kimber SJ and Elstein M (1995) CD44 is expressed throughout preimplantation human embryo development Human Reproduction 10 425-430

Crosier AE, Farin PW, Dykstra MJ, Alexander JE and Farin CE (2001) Ultrastructural morphometry of bovine blastocysts produced in vivo or in vitro. Biology of Reproduction 64 1375-1385

Crowe JH and Crowe LM (2000) Preservation of mammalian cells: learning nature's tricks Nature Biotechnology 18 145-146

Dittmann J, Keller C and Harisch G (1998) Inhibition of adenylate cyclase of rat hepatic membranes by glycosaminoglycans Life Sciences $\mathbf{6 3}$ 2199-2208

Eppig JJ (1979) FSH stimulates hyaluronic acid synthesis by oocytecumulus cell complexes from mouse preovulatory follicles Nature $\mathbf{2 8 1}$ 483-484

Eroglu A, Russo MJ, Bieganski R, Fowler A, Cheley S, Bayley H and Toner M (2000) Intracellular trechalose improves the survival of cryopreserved mammalian cells Nature Biotechnology 18 163-167

Fair T, Lonergan P, Dinnyes A, Cottell DC, Hyttel P, Ward FA and Boland MP (2001) Ultrastructure of bovine blastocysts following cryopreservation: effect of method of blastocyst production Molecular Reproduction and Development 58 186-195

Fraser JRE, Laurent TC and Laurent UBG (1997) Hyaluronan: its nature, distribution, functions and turnover Journal of Internal Medicine $\mathbf{2 4 2}$ $27-33$

Furnus CC, de Matos DG and Martinez AG (1998) Effect of hyaluronic acid on development of in vitro produced bovine embryos Theriogenology 49 1489-1499

Gardner DK, Rodriguez-Martinez H and Lane M (1999) Fetal development after transfer is increased by replacing protein with the glycosaminoglycan hyaluronan for mouse embryo culture and transfer Human Reproduction 14 2575-2580

Ginsberg L and Hillman N (1973) ATP metabolism in cleavage-stage mouse embryos Journal of Embryology and Experimental Morphology 30 267-282

Hamashima N (1982) Effects of hyaluronic acid on the peri-implantational development of mouse embryos in vitro. Development, Growth and Differentiation 24 353-357

Hoae K, Savani RC, Wang C, Yang B and Turley EA (1993) Identification of hyaluronan binding proteins using a biotinylated hyaluronan probe Connective Tissue Research 30 117-126

Jackson RL, Busch SJ and Cardin AD (1991) Glycosaminoglycans: molecular properties, protein interactions and role in physiological processes Physiological Reviews 71 481-539

Kano K, Miyano T and Kato S (1998) Effects of glycosaminoglycans on the development of in vitro-matured and -fertilized porcine oocytes to the blastocyst stage in vitro. Biology of Reproduction 58 1226-1232

Laurent TC and Fraser JRE (1992) Hyaluronan Journal of the Federation of American Societies for Experimental Biology 6 2397-2404

Lee CN and Ax RL (1984) Concentration and composition of glycosaminoglycans in the female bovine reproductive tract Journal of Dairy Science 67 2006-2009

Marquant-Le Guienne B, Guyader-Joly C, Ponchon S, Delalleau N and Humblot $\mathbf{P}$ (1998) Effect of hyaluronic acid in a serum free maturation medium on bovine embryo development Theriogenology 51386 (Abstract)

Massip A, Mermillod P and Dinnyes A (1995) Morphology and biochemistry of in vitro produced bovine embryos: implications for their cryopreservation Human Reproduction 10 3004-3011

Miyoshi K, Umezu M and Sato E (1999) Effect of hyaluronic acid on the development of porcine 1-cell embryos produced by conventional or new in vitro maturation/fertilization system Theriogenology $\mathbf{5 1}$ $777-784$

Nagyova E, Vanderhyden BC and Prochazka R (2000) Secretion of paracrine factors enabling expansion of cumulus cells is developmentally regulated in pig oocytes Biology of Reproduction 63 1149-1156
Nishida K, Nakakoga Y, Sato N, Kawakami S, Mukai T, Sasaki H, Sakaeda T and Nakamura J (2000) Effect of viscous additives on drug absorption from the liver surface in rats using phenol red as a model European Journal of Pharmacy and Biopharmacology 50 397-402

Ohboshi S, Fujihara N, Yoshida T and Tomagane H (1998) Ultrastructure of bovine in vitro-produced blastocysts cryopreserved by vitrification Zygote 6 17-26

Palasz A, Alkemade S and Mapletoft RJ (1993) The use of sodium hyaluronate in freezing media for bovine and murine embryos Cryobiology 30 172-178

Palasz AT, Thundathil J, de la Fuente R and Mapletoft RJ (2000) Effect of reduced concentration of glycerol and various macromolecules on the cryopreservation of mouse and cattle embryos Cryobiology 41 35-42

Parrish JJ, Susko-Parrish JL, Leibfried-Rutledge ML, Critser ES, Eyestone WH and First NL (1986) Bovine in vitro fertilization with frozen-thawed semen Theriogenology 25 591-600

Rodriguez-Martinez H, Larsson B, Pertoft H and Kjellen L (1998) GAGs and spermatozoa competence in vivo and in vitro. In Gametes: Development and Function pp 239-272 Eds A Lauria, G Enne, F Gandolfi and L Gianaroli. Serono Symposia, Roma

Scott JE (1992) Supramolecular organization of extracellular matrix glycosaminoglycans, in vitro and in the tissues Journal of the Federation of American Societies for Experimental Biology 6 2639-2645

Stojkovic M, Wolf E, Büttner M, Berg U, Charpigny G, Schmitt A and Brem G (1995a) Secretion of biologically active interferon tau by in vitroderived bovine trophoblastic tissue Biology of Reproduction 53 1500-1507

Stojkovic M, Willemsen D, Büttner M and Wolf E (1995b) Development and interferon production by frozen-thawed in vitro derived bovine trophoblastic vesicles Theriogenology 43326 (Abstract)

Stojkovic M, Zakhartchenko V, Brem G and Wolf E (1997) Support for the development of bovine embryos in vitro by secretions of bovine trophoblastic vesicles derived in vitro. Journal of Reproduction and Fertility 111 191-196

Stojkovic M, Büttner M, Zakhartchenko V, Brem G and Wolf E (1998a) A reliable procedure for differential staining of in vitro produced bovine blastocysts: comparison of tissue culture medium 199 and Menezo's B2 medium Animal Reproduction Science 50 1-9

Stojkovic M, Boxhammer K, Zakhartchenko V and Wolf E (1998b) Plant extracts (Guar gum) support development of bovine embryos in vitro. Theriogenology 49219 (Abstract)

Stojkovic M, Thompson JG and Tervit HR (1999a) Effects of hyaluronic acid supplementation on in vitro development of bovine embryos in a twostep culture system Theriogenology 51254 (Abstract)

Stojkovic M, Büttner M, Zakhartchenko V, Riedl J, Reichenbach HD, Wenigerkind H, Brem G and Wolf E (1999b) Secretion of interferon-tau by bovine embryos in long-term culture: comparison of in vivo derived, in vitro produced, nuclear transfer and demi embryos Animal Reproduction Science 55 151-162

Stojkovic M, Westesen K, Zakhartchenko V, Stojkovic P, Boxhammer K and Wolf E (1999c) Coenzyme $Q_{10}$ in submicron-size dispersion improves development, cell proliferation, and hatching of in vitro produced bovine embryos Biology of Reproduction 61 541-547

Stojkovic M, Kölle S, Zakhartchenko V, Stojkovic P, Sinowatz F and Wolf E (2001a) Effects of estrous cow serum/bovine serum albumin on early cleavage, blastocyst rate, cell number, and ultrastructural configuration of in vitro produced bovine embryos Advances in Reproduction V 35-44

Stojkovic M, Machado SA, Stojkovic P, Zakhartchenko V, Hutzler P, Goncalves PB and Wolf E (2001b) Mitochondrial distribution and adenosine triphosphate-content of bovine oocytes before and after in vitro maturation: correlation with morphological criteria and developmental capacity after in vitro fertilization and culture Biology of Reproduction 64 904-909

Stojkovic M, Peinl S, Stojkovic P, Zakhartchenko V, Thompson JG and Wolf E (2001c) High concentration of hyaluronic acid in culture medium increases the survival rate of frozen/thawed in vitro produced bovine embryos Theriogenology 55317 (Abstract)

Suchanek E, Simunic V, Juretic D and Grizelj V (1994) Follicular fluid contents of hyaluronic acid, follicle-stimulating hormone and steroids 
relative to the success of in vitro fertilization of human oocytes Fertility and Sterility 62 347-352

Tervit HR, Whittingham DG and Rowson LEA (1972) Successful culture in vitro of sheep and cattle ova Journal of Reproduction and Fertility $\mathbf{3 0}$ 493-497

Toole BP (1997) Hyaluronan in morphogenesis Journal of Internal Medicine $24235-40$

Vajta G, Hyttel P and Callesen H (1997) Morphological changes of in vitro produced bovine blastocysts after vitrification, in-straw direct rehydration, and culture Molecular Reproduction and Development 48 9-17
Valcarcel A, de Matos DG and Furnus CC (1999) The hyaluronic acid receptor (CD44) is expressed in bovine oocytes and preimplantational stage embryos Theriogenology 51193 (Abstract)

Received 8 November 2001

First decision 15 January 2002.

Revision received 1 February 2002.

Accepted 26 February 2002. 